\title{
Unidade de ensino potencialmente significativa como elemento facilitador da aprendizagem de ciências biológicas no ensino médio
}

\author{
Potentially significant teaching unit as a facilitating element for the learning of biological \\ sciences in high school
}

\author{
B. G. Correia ${ }^{1 *}$; C. R. P. Guimarães ${ }^{2}$ \\ ${ }^{1}$ Pós-Graduação em Ensino de Ciências e Matemática, Universidade Federal de Sergipe, 49100-000, São Cristóvão- \\ SE, Brasil \\ ${ }^{2}$ Departamento de Biologia/Laboratório de Ecossistemas Costeiros, Pós-Graduação em Ensino de Ciências e \\ Matemática, Universidade Federal de Sergipe, 49100-000, São Cristóvão-SE, Brasil
}

*brunagc23@gmail.com

(Recebido em 26 de maio de 2020; aceito em 27 de julho de 2020)

\begin{abstract}
O presente estudo teve o objetivo de investigar o desenvolvimento da Aprendizagem Significativa (AS) através da utilização de uma Unidade de Ensino Potencialmente Significativa (UEPS) no estudo dos microorganismos em uma turma de ensino médio. O trabalho fundamentou-se na Teoria da Aprendizagem Significativa (TAS) desenvolvida por David P. Ausubel, tendo como aportes teóricos trabalhos de autores como Moreira, Masini, Krasilchik e Motokane, dentre outros. Foi utilizada uma abordagem qualitativa e elementos da Análise Textual Discursiva na interpretação dos dados. Questionários, observações in loco e gravações das aulas foram utilizados para identificar evidências de AS e dificuldades encontradas pelos alunos para a participação no processo. A maioria dos alunos expressou evidências de AS no material analisado. O tempo utilizado nas aulas foi considerado a principal variável capaz de interferir no desenvolvimento da AS, outras dificuldades foram evidenciadas na compreensão significativa do conteúdo, como a falta de conhecimentos prévios, predisposição para aprender e obstáculo epistemológico. Concluindo foi possível demonstrar que a utilização da UEPS foi eficaz, pois mesmo diante das adversidades, presentes no cotidiano escolar, os aprendizes conseguiram dar significado ao conteúdo estudado. Desta forma a AS pode ser alcançada em contextos diversificados, passíveis de variáveis cotidianas, através da estruturação e implementação dos métodos e instrumentos de ensino baseados no que propõe as UEPS.

Palavras-chave: UEPS, Teoria da Aprendizagem, Ensino de Biologia.
\end{abstract}

This study aimed to investigate the development of Meaningful Learning (ML) through the using of a Potentially Meaningful Teaching Unit (PMTU) in the study of microorganisms in a high school class. The work was based on the Theory of Meaningful Learning (TML) developed by David P. Ausubel, it has as incentive theoretical contributions works by authors such as Moreira, Masini, Krasilchik and Motokane, among others. A qualitative approach such and elements of the Textual Discursive Analysis were used to interpret the data. Questionnaires, on-site observations and class recordings were used to identify evidences of ML and difficulties found by students in the participating process. Most students expressed evidences of ML in the analyzed material. The time used in classes was considered the main able variable of interfering in the development of ML, others difficulties were evidenced in the significant understanding of the content, such as the lack of prior knowledge, predisposition to learn and epistemological obstacle. In conclusion, it was possible to demonstrate that the use of PMTU was effective, because even in the face of adversities, in the school routine, the apprentices managed the meaning to the studied content. In this case, ML can be achieved in diverse contexts, subject to daily variables, through the structuring and implementation of teaching methods and instruments based on what the PMTU proposes.

Keywords: PMTU, Learning Theory, Biology Teaching.

\section{INTRODUÇÃO}

Muito se tem falado sobre maneiras de fazer o ensino de Biologia contribuir de uma forma mais substancial na vida dos educandos. Entretanto, nem sempre esta é uma tarefa fácil para o professor, que encontra na sala de aula resistência a mudanças. Motokane (2015) [1] descreve o ensino de Biologia como um ensino que carrega o estigma de ter uma quantidade excessiva de terminologias além de descrições extensas de processos e estruturas. Esses fatos dificultam muito a aprendizagem 
dos conteúdos desta disciplina curricular, que trata de temas extremamente relevantes para formação do aluno.

No ensino da Biologia, também nos deparamos com uma dicotomia evidenciada por Krasilchik (2011) [2]: pode ser uma das disciplinas mais relevantes e merecedoras de atenção dos alunos ou, uma das mais insignificantes e pouco atraentes, dependendo de como for ensinado. Em síntese, a forma como os conteúdos são apresentados aos alunos, pode influenciar o relacionamento dos mesmos com o conhecimento.

Dentre os diversos temas apresentados no ensino médio nos currículos de Biologia, temos a Microbiologia, assunto que trata tanto da diversidade da vida como de diversas formas de interação dos micro-organismos com os seres humanos. É um assunto de grande importância uma vez que o senso comum os evidencia normalmente como danosos mas, ao contrário, muitos deles são benéficos tanto para o nosso organismo quanto para o ambiente, conforme explicitado por Cabelleira (2018) [3].

Este assunto é abordado nos PCN+, no tema dois, que evidencia a importância de tratar de aspectos relacionados ao cotidiano dos alunos, que podem por meio deste conhecimento melhorar o ambiente em que vivem:

[...] graças as ciências ambientais, sociais e da vida, como a fisiologia, a microbiologia, os alunos poderão nas situações de aprendizagem, aprofundar seu entendimento sobre as condições de vida e saúde da população e se preparar para uma ação de intervenção solidária que vise a transformação dessas condições. Brasil (2002) [4].

Como define Bezerra (2016) [5], “[...] a microbiologia é a ciência que estuda os microorganismos, buscando compreender os aspectos da vida desses seres e sua relação com os demais seres vivos e com o ambiente". Este tipo de conteúdo é considerado um grande desafio para o ensino de Ciências e Biologia, segundo Antunes et al. (2012) [6], por ser abstrato, uma vez que trata de organismos não visíveis a olho nu e a maioria das escolas não dispõe de laboratórios com condições de visualização ou manipulação. No entanto, este conteúdo tem demonstrado sua relação com abordagens sobre saúde, higiene e meio ambiente que são presentes em nosso cotidiano.

Neste sentido ao falar sobre formas de abordagem dos conteúdos em microbiologia, Bezerra (2016) [5] expõe que a maneira como ocorre o ensino de tal conteúdo ainda é pouco significativa e desconexa do contexto dos estudantes. Esse autor propõe atividades que possam evidenciar a relação com o cotidiano do aluno, com embasamento nos princípios da AS. Proporcionando melhor significados naquilo que o aluno aprende e pode posteriormente utilizar em situações fora do contexto escolar.

Em vista disso, é necessária uma abordagem metodológica, em sala de aula, que consiga despertar no aluno a atenção para a importância de compreender esse conhecimento de forma significativa. Porém, para desenvolver uma aprendizagem que seja significativa para o aluno existe um caminho a percorrer: como fazer o conhecimento chegar aos alunos e desenvolver neles uma conexão entre aquilo que já conhecem do ambiente em que vivem e o conhecimento cientifico? como fazer com que os conhecimentos biológicos sejam apropriados de forma significativa pelos alunos?

Lima et al. (2012) [7], nesse sentido descrevem que:

[...] o processo educativo requer uma aprendizagem significativa que atenda a aprendizagem de conceitos de modo que, ao ensinar, o professor apresente significados contextuais aos alunos e que estes possam compreendê-los, ancorando-se em conceitos já estabelecidos cognitivamente e possam posteriormente compartilha-los.

Então, é fundamental um suporte teórico que contribua com as escolhas didáticas e metodológicas do professor em suas aulas, ajudando-o a compreender os processos de aprendizagem e a buscar respostas para as adversidades cotidianas de ambientes tão singulares quanto as salas de aula.

Neste estudo discutiremos o Ensino de Microbiologia sob a ótica de uma teoria cognitiva apoiada nos trabalhos de Moreira (2015) [8], que trata principalmente dos processos mentais e se ocupa da atribuição de significados, da compreensão, transformação, armazenamento e uso das 
informações envolvidas na cognição. Desta forma é importante considerar que muitos são os aspectos presentes nos processos de aprendizagem e a busca por formas de se chegar a ela de maneira mais efetiva é contínua. Assim, Portilho (2011) [9] aponta que, no processo de aprendizagem encontramos diferentes concepções e teorias que evidenciam os valores e as crenças que norteiam nossa maneira de ser, pensar, sentir, agir e interagir.

Pelizzari et al. (2002) [10] dão significado as boas práticas de ensino quando dizem que: "[...] a intervenção educativa precisa, portanto, de uma mudança da ótica substancial a qual não somente abranja o saber, mas também o saber fazer, não tanto o aprender como o aprender a aprender [...]". Desta forma, planejar e executar as aulas levando em consideração tais fatores pode facilitar o desenvolvimento de uma aprendizagem significativa, ajudando a minimizar as lacunas presentes no ensino de Biologia, proporcionando o desenvolvimento dos conteúdos de forma que os alunos atribuam maior significado ao que aprendem e consigam, então, utilizar estes conhecimentos em suas vidas fora da escola.

Partindo de pressupostos cognitivos, David P. Ausubel (1963) [24] propôs uma teoria que, através de suas especificações e orientações, tem o intuito de desenvolver nos alunos uma aprendizagem realmente significativa, onde esses possam se apropriar dos conhecimentos fornecidos na aula e, a partir deles, desenvolver em sua estrutura cognitiva um novo conhecimento relacionado com o já existente, proporcionando um maior significado, um maior sentido para a aprendizagem $[8,11]$.

O ponto principal da Teoria da Aprendizagem Significativa de Ausubel (2003) [20] concentrase no fato de que, para sua ocorrência, é necessário que uma nova ideia, um novo conhecimento possa se relacionar com um conhecimento já presente na estrutura cognitiva do aprendiz e, a partir daí esses dois conhecimentos, tanto o existente quanto o novo, se modificam e proporcionam ao indivíduo um novo sentido para aquilo que se aprende.

No entanto, o crucial do desenvolvimento de uma aprendizagem realmente significativa, é que os conhecimentos e ideias expostos ao aprendiz sejam relacionados por ele, de forma não literal (não ao pé da letra), e não arbitrária [8]. "A Aprendizagem Significativa é a aquisição de novos conhecimentos com significado, compreensão, criticidade e possibilidades de aplicação desses conhecimentos em explicações, argumentações e soluções de situação-problema" [12].

Além das características já mencionadas, é crucial considerar três fatores primordiais para a ocorrência da AS:

1. A estrutura cognitiva existente é a variável independente que mais influência, podendo facilitar, limitar ou inibir a aprendizagem significativa de um certo conhecimento; 2. a predisposição para aprender, o querer aprender, a intencionalidade do aprendiz é outro fator fundamental; o ser humano poderá aprender de maneira significativa se quiser aprender; por alguma razão, deve ter a intenção de aprender; 3. os materiais de aprendizagem devem ser potencialmente significativos; devem fazer sentido para o aprendiz. Masini e Moreira (2017) [12].

Desta forma, as estratégias e métodos de ensino são de suma importância para o bom desenvolvimento de uma aprendizagem satisfatória e consequentemente significativa. Concatenado aos conceitos da Teoria da Aprendizagem Significativa, Moreira (2011a) [13], em seus estudos sobre as potencialidades dos postulados de Ausubel, propõe o que se denominou Unidades de Ensino Potencialmente Significativa (UEPS).

As UEPS contêm instrumentos e processos que dão ênfase a atividades colaborativas e troca de ideias entre os alunos. Elas também discorrem sobre como os conteúdos podem ser organizados e qual a melhor forma de tratá-los em sala de aula. As UEPS possuem uma organização e passos específicos, que servem de suporte e ponto de partida para a facilitação da aprendizagem significativa.

O conceito de UEPS foi desenvolvido por Moreira (2011b) [14] como uma sequência de ensino baseada nos elementos constituintes da Teoria de Aprendizagem Significativa. Sendo considerado um instrumento de ensino com capacidade de facilitar a AS, as UEPS possuem passos e fases específicas que contemplam processos como a diferenciação progressiva e reconciliação integrativa, pilares da teoria, assim como propõem momentos variados para atividades colaborativas e resolução de problemas. 
Neste sentido, entende-se que "[...] as unidades de ensino estão alicerçadas ao processo e as circunstâncias que se propõe a aprendizagem, que é distinta fundamentalmente das características e natureza do material de ensino" [15].

Moreira (2011a) [13], ao construir um diagrama de V sobre as UEPS, considera que o maior valor desta, está no fato de que se trata de uma sequência de ensino teoricamente fundamentada e, portanto, com maior potencial de desenvolver uma Aprendizagem Significativa. Desta forma, cabe ao professor selecionar os conteúdos, os métodos e as estratégias mais apropriados que o ajudem a alcançar os objetivos da aprendizagem. Neste sentido, as UEPS estão relacionadas na busca por melhor ordenar e guiar a prática docente.

Diante do exposto e da motivação para realização da pesquisa, surgiram os seguintes questionamentos: Como se desenvolve a Aprendizagem Significativa através da utilização de uma Unidade de Ensino Potencialmente Significativa no estudo dos micro-organismos no ensino médio? Quais as variáveis que poderiam interferir nesse processo?

Foi definido como objetivo, investigar sobre como se dá o desenvolvimento da Aprendizagem Significativa (AS), através da utilização de uma Unidade de Ensino Potencialmente Significativa (UEPS), para o estudo dos microrganismos em uma turma de ensino médio. Para alcança-lo foi proposta: 1) a identificação das evidências de AS durante o desenvolvimento da UEPS; 2) a análise das variáveis que podem interferir no processo de AS, desenvolvida durante a UEPS e; 3) a verificação das dificuldades dos alunos que podem interferir no processo de AS que foi desenvolvido durante a UEPS.

\section{MATERIAL E MÉTODOS}

O presente estudo pode ser caracterizado como uma pesquisa de cunho qualitativo, cuja definição está explicitada por Flick (2009) [16] como "[...] tipo de pesquisa que visa a abordar o mundo 'lá fora' (e não em contextos especializados de pesquisa, como os laboratórios) e entender, descrever e, às vezes, explicar os fenômenos 'de dentro'.”. Ludke e André (2015) [17] reforçam a abordagem do autor supracitado ao descreverem que "A pesquisa qualitativa supõe o contato direto e prolongado do pesquisador com o ambiente e a situação que está sendo investigada, via de regra, pelo trabalho intensivo de campo".

O estudo foi desenvolvido em quatro fases envolvendo: 1) a revisão bibliográfica, 2) a submissão da proposta ao comitê de ética, o qual foi aprovado com o número do parecer 3.248.343, 3) a elaboração da UEPS e 4) a execução da proposta que envolveu a aplicação das atividades, a coleta e a análise dos dados. A pesquisa foi realizada em uma escola da rede estadual de ensino, situada no estado de Alagoas (AL) com as aulas sendo ministradas pela pesquisadora, concomitantemente a coleta de dados. O estudo teve início em março de 2019, no momento em que se iniciava o período letivo.

Ocorreu um primeiro contato com a escola, para conhecimento e familiarização com os aspectos de funcionamento da Instituição escolar. Posteriormente a esta primeira visita foi definido, junto com o corpo docente da escola, o tema de estudo e, a partir disso, partiu-se para a elaboração da UEPS dentro do tempo disponibilizado pela escola para a realização da atividade.

A validação do material, tanto da UEPS quanto dos questionários, iniciais e finais, foram feitas pelos membros da escola, os professores de Biologia e componentes da coordenação, com a consequente reformulação dos mesmos. Para dar início as atividades em sala de aula, foi elaborada uma UEPS, adaptada ao conteúdo curricular Micro-organismos, cujos passos sequenciais estão resumidamente descritos no Quadro 1.

A etapa da coleta de dados ocorreu simultaneamente à aplicação da UEPS. A coleta foi realizada durante 5 encontros ocorridos na escola (cada encontro ocorreu em duas/horas aulas conjugadas). As informações, que se constituíram nos dados da pesquisa, tiveram como instrumentos o questionário (utilizado como avaliação somativa), observação in loco, anotações posteriores a cada aula em diário de campo e gravações das aulas em vídeo e áudio. 
Quadro 1- Etapas da montagem da UEPS sobre os micro-organismos utilizados nesta pesquisa.

\begin{tabular}{|c|c|}
\hline PASSOS & ATIVIDADES \\
\hline $\mathbf{1}^{\circ}$ & $\begin{array}{l}\text { Escolha do conteúdo micro-organismo (Vírus, Bactérias, Protozoários e Fungos) e definição } \\
\text { dos objetivos: } \\
\bullet \quad \text { Caracterizar o grupo dos micro-organismos; } \\
\bullet \quad \text { Diferenciar os subgrupos; } \\
\text { - } \quad \text { Eelacionar e reconhecer a presença desses seres no cotidiano; } \\
\text { A escolha do assunto a ser tratado foi uma definição da escola para que todas as turmas, do } \\
\text { mesmo nível escolar seguissem um mesmo conteúdo assim como o número de horas/aula } \\
\text { disponibilizados. Os objetivos foram então definidos e a partir deles as atividades foram } \\
\text { organizadas. }\end{array}$ \\
\hline $2^{\circ}$ & $\begin{array}{l}\text { Realizar atividades que propiciem ao aluno externalizar seu conhecimento prévio: } \\
\bullet \quad \text { Resolução de questionário com questões de nível elementar (pré-teste); } \\
\bullet \quad \text { Construção de mapa mental na lousa em conjunto com os alunos. } \\
\text { Foi apresentado aos alunos o projeto a ser desenvolvido, compartilhando os passos da UEPS. } \\
\text { A externalização dos subsunçores se deu após a explicação do que era um mapa conceitual e } \\
\text { a construção de forma conjunta do mesmo }\end{array}$ \\
\hline $3^{\circ}$ & $\begin{array}{l}\text { Aplicar texto introdutório, utilizado como organizador prévio (com aspectos introdutórios do } \\
\text { tema, abrangendo características de cada grupo de micro-organismos): } \\
\text { Estimular a discussão e problematização do tema. } \\
\text { Discutir, no escopo do movimento CTSA (Ciência, Tecnologia, Sociedade e Ambiente), } \\
\text { o tema, sua importância para a sociedade e para a formação cidadã. } \\
\text { O texto utilizado como organizador prévio foi elaborado a partir da junção entre dois } \\
\text { fragmentos introdutórios dos capítulos } 2 \text { e } 3 \text { do livro didático utilizado, os quais tratavam dos } \\
\text { aspectos mais elementares relacionados aos quatro grupos de micro-organismos estudados } \\
\text { (Amabis, José Martino, Biologia moderna. } 1 \text { edição- São Paulo: Moderna 2016). }\end{array}$ \\
\hline $4^{\circ}$ & $\begin{array}{l}\text { Introduzir o conhecimento/conteúdo: aula expositiva dialogada com estímulo a participação } \\
\text { do aluno considerando o princípio da diferenciação progressiva. } \\
\text { Organizar o conteúdo (Seres Vivos) dos aspectos gerais para os específicos, situando os } \\
\text { micro-organismos nessa classificação. } \\
\text { Disponibilizar e apresentar mapa conceitual com as características mais gerais e elementares } \\
\text { dos grupos estudados. }\end{array}$ \\
\hline $5^{\circ}$ & $\begin{array}{l}\text { Retomar os aspectos gerais do conteúdo, utilizando aula expositiva dialogada (com uso de } \\
\text { TICs - Tecnologias da Informação e Comunicação). } \\
\text { Introduzir aspectos mais complexos sobre o tema como: reprodução, importância econômica } \\
\text { e ecológica, diferenças entre os grupos. } \\
\text { Realizar atividades colaborativas: } \\
\text { • Formar grupos para construção de mapas conceituais, com posterior } \\
\text { apresentação; } \\
\text { • Formar grupos para a elaboração de painel integrado. }\end{array}$ \\
\hline $6^{\circ}$ & $\begin{array}{l}\text { Recapitular o que foi estudado sobre o conteúdo, reconciliando e integrando as ideias já } \\
\text { estudadas; } \\
\text { Finalizar a atividade com uma breve exposição relacionando os micro-organismos com a } \\
\text { saúde humana em um nível mais alto de complexidade; } \\
\text { Apresentar um seminário (atividade colaborativa) com a construção de cartazes com o intuito } \\
\text { de prevenção de doenças causadas por esses seres microscópicos. }\end{array}$ \\
\hline $7^{\circ}$ & $\begin{array}{l}\text { Avaliar de forma somativa utilizando questionário com questões de nível mais complexo } \\
\text { sobre o tema (pós-teste). }\end{array}$ \\
\hline
\end{tabular}

Fonte: Dados da pesquisa.

É necessário considerar que o questionário foi desenvolvido levando em consideração aspectos importantes para a AS do aluno, também levando em conta o que de mais significativo o conteúdo traz, e que deveria ser apreendido pelo aluno.

O questionário inicial possuia como aspecto norteador de suas questões a preocupação com a aprendizagem de conceitos relacionados a: O que são os Microrgnismos? Quais as diferenças entre os grupos estudados? Qual a relação existente entre esses seres e nós humanos? Qual o papel dos 
micro-organismos na natureza em geral? O questionário final utilizado após a aplicação da UEPS, para identificar as evidências de AS por meio das respostas dos alunos, continha 6 questões abertas para o aluno. Nestas questões finais, o aluno, além de apresentar o que aprendeu do conteúdo também deveria se posicionar acerca da importância do mesmo. A análise desse questionário ocorreu por meio da Análise Textual Discursiva (ATD), proposta por Moraes e Galiazzi (2011) [18].

O uso da ATD envolveu as etapas básicas, que os autores da proposta [18] descreveram como um ciclo: 1) desmontagem dos textos; 2) estabelecimento de relações; 3) captação do novo emergente; 4) estabelecimento de um processo auto-organizado:

Etapa 1 - a desmontagem dos textos ocorreu por meio de uma análise geral das respostas dos alunos nas questões descritas na avaliação somativa. Nesta etapa foram considerados os pontos mais significativos das respostas dos alunos nos questionamentos e estes foram transcritos para a formação do metatexto. Para os autores do método essa etapa consiste em "examinar os materiais em seus detalhes, fragmentando-os no sentido de atingir unidades constituintes, enunciados referentes aos fenômenos estudados".

Etapa 2 - se constituiu em uma análise minuciosa e observação do corpus, buscando as relações mais próximas entre as ideias expressas pelos alunos, em suas respostas aos questionamentos sobre o tema estudado. "Processo denominado de categorização, implicando construir relações entre as unidades de base, combinando-as e classificando-as no sentido de compreender como esses elementos unitários podem ser reunidos na formação de conjuntos mais complexos".

Etapa 3 - a captação de um novo emergente foi caracterizada como a fase onde ocorreu a análise geral das categorias expressas e os significados que estas representam junto à teoria estudada, na busca de uma nova compreensão do tema estudado. "A intensa impregnação nos materiais da análise desencadeada pelos dois estágios anteriores possibilita a emergência de uma compreensão renovada do todo".

Etapa 4 - processo auto-organizado; é a etapa em que surgem as novas compreensões e significados.

Para preservar a identidade dos participantes da pesquisa eles foram representados por códigos em que a letra A refere-se a aluno e o número que se segue é a designação de cada aluno da turma: $\mathrm{A} 1, \mathrm{~A} 2, \mathrm{~A} 3 \mathrm{e}$ assim por diante.

A definição das características capazes de evidenciarem ou não a AS por meio da ATD se deu por categorias estabelecidas a priori, baseadas em Moraes e Galiazzi (2011) [18],

[...] no processo de categorização a priori ou fechado, às categorias são predeterminadas, ou seja, fornecidas de antemão. A origem das categorias nesse caso será geralmente alguma teoria em que se fundamenta a pesquisa, com as categorias sendo deduzidas dessa teoria.

Para encontrar as evidências de ocorrência de AS no período de aplicação da UEPS, foram consideradas aquelas descritas por Moreira (2011a) [13], que consistem na mudança do comportamento do aluno durante as aulas, captação de significados, compreensão, capacidade de explicar, de aplicar o conhecimento para resolver situações problema, e também quando o aluno consegue responder a questionamentos de forma diferente daquela que viu no conteúdo instrucional, descrevendo a sua maneira, como se deu a sua compreensão sobre o tema.

Os alunos foram classificados em cada categoria de acordo com suas respostas ao questionário, as respostas que convergiam com a definição de da categoria de acordo com o referencial Ausubeliano para as evidências de aprendizagem significativa.

Para verificar as dificuldades de desenvolver uma aprendizagem significativa do conteúdo estudado na UEPS e reconhecer as variáveis que podem ter interferido nesse processo, foram utilizadas as observações in loco e as anotações no diário de campo, assim como os vídeos das aulas, durante a aplicação da UEPS, buscando evidênciar as características comportamentais, de performace e desempenho dos alunos em situações do cotidiano escolar no contexto estudado. 


\section{RESULTADOS E DISCUSSÃO}

Uma das diferenças mais marcantes entre os processos ditos de aprendizagem e os de AS, é como ocorrem os processos avaliativos, pois no segundo, não se pode simplesmente inferir se houve ou não a AS, é preciso buscar evidências de sua ocorrência com os aprendizes. Neste caso, é importante sempre considerar ao analisar as colocações dos alunos o que menciona Lemos (2011) [19]:

[...] de acordo com a teoria, o significado atribuido pelo sujeito que aprende pode ser ou não correto pelo ponto de vista científico e também é o sujeito que, de forma consciente ou não, confere importância ao conhecimento ao atribuir-lhe utilidade para sua vida cotidiana.

Desta forma, existem alguns aspectos que devem ser observados na busca das evidências da AS como a dialogicidade do ensino, uma avaliação contínua e considerar todo o processo de aprendizagem e não apenas parte do mesmo [12].

Processos esses que foram observados e levados em consideração durante todo o desenvolvimento da UEPS, como será descrito abaixo, nos cinco encontros do desenvolvimento da mesma.

Primeiro encontro: foi feita uma apresentação geral à turma sobre a pesquisa e foram sanadas as dúvidas dos alunos. Também foram disponibilizados os termos de Assentimento e Consentimento. Ainda nesta aula, num segundo momento, foi disponibilizado um questionário para atuar como pré-teste, para cada aluno, com o intuito de verificar os conhecimentos prévios sobre o conteúdo Micro-organismos. Após responderem ao pré-teste, os alunos, junto com a professora/presquisadora, contruíram na lousa um mapa mental, com seus conhecimentos prévios sobre o tema.

Segundo encontro: neste encontro, foi feita uma revisão dos aspectos tratados na aula anterior, seguido de uma exposição introdutória do conteúdo, considerando os aspectos de diferenciação progressiva na organização do conteúdo. Após a exposição, foi distribuído para os estudantes um texto (organizador prévio) para leitura e discussão, para finalizar este momento foi disponibilizado para os alunos um Mapa Conceitual (MC) com as características e conceitos mais elementares a serem estudadas em cada um dos quatro grupos de micro-organismos.

Terceiro encontro: neste encontro, assim como recomendado, e sempre de acordo com os princípios de diferenciação progressiva e reconciliação integrativa, foi abordado por meio de exposição dialogada, com a utilização de projetor multimidia, características e diferenças existentes entre os quatro grupos de micro-organismo. Terminado o momento de exposição e interação entre os alunos com o tema, a turma foi dividida em grupos de quatro a cinco participantes para a primeira atividade colaborativa, referente à construção de um Mapa Conceitual.

Quarto encontro: neste momento foi finalizada a atividade colaborativa dos $\mathrm{MC}$, com a apresentação, por cada grupo, do seu mapa, em seguida ocorreu à troca de componentes dos grupos para a segunda atividade colaborativa representada pelo Painel Integrado (nesta atividade dividi-se a turma em equipes, cada aluno da equipe recebe uma letra ou número: a, b, c, d, cada equipe refleti e discute sobre o tema, é dado um tempo estimado, depois as equipes se dividem para formar outras. Os que tiverem a letra "a" formarão uma nova equipe e o mesmo acontecerá com os que tiverem a letra b, c, d. Agora todos partilharão o que foi debatido nas equipes anteriores. No final da dinâmica todos os participantes deverão ter tomado conhecimento de todas as reflexões feitas).

Quinto encontro: no último encontro, houve uma breve recapitulação do conteúdo visto até o momento, assim como foram feitas algumas considerações, em um nível mais complexo de conhecimento, sobre a relação dos micro-organismos com os seres humanos e mais especificamente com a saúde humana, sendo em seguida apresentado um seminário pelos alunos que abordava essa problemática. Após as apresentações foi distribuído aos alunos um questionário final (Avaliação Somativa).

Após a análise da avaliação somativa, foram criadas as categorias para demonstrar evidências de AS nas respostas dos alunos, após o processo de esudo dos micro-organismos por meio da UEPS.

As quatro categorias propostas a priori como evidência de AS foram: 
Categoria 1: Capacidade de explicar - neste trabalho consideramos capacidade de explicar como sendo a capacidade do aluno organizar suas ideias, utilizando os conhecimentos adquiridos sobre o tema estudado, conseguindo expressar de forma coerente e clara seu conhecimento, expressando-o de forma diferente daquela constante no material instrucional. Masini e Moreira (2017) [12] descrevem que "a aprendizagem significativa de novos conhecimentos com significado ocorre quando existir a compreensão e possibilidades de aplicação desses conhecimentos em explicações, argumentos e soluções de situação problema".

Neste caso, evidenciamos que 15 alunos $(39,4 \%)$ expressaram seus conhecimentos em suas respostas ao questionário, demonstrando compreensão ao explicar as características dos seres estudados e relacioná-las a vida cotidiana. Como pode ser evidenciado nas respostas dos alunos 14 e 32 .

A14: "os vírus são seres acelulares que precisam de um hospedeiro, reproduzem dentro de células e causam doenças prejudiciais as pessoas, mas muitas doenças podem ser controladas e também tem tratamento.".

A32: "os fungos são heterotrófos, estão presentes em alimentos como, por exemplo, nos pães, mofos, as leveduras é um tipo de fungo, que se usa na fabricação de alimentos e bebidas, os fungos também são eucariontes, podemos encontrar vários tipos desses seres no nosso dia a dia, como os fungos e bactérias..."

Assim como menciona Moreira (2015) [8], o crucial no desenvolvimento de uma aprendizagem realmente significativa, é que os conhecimentos e ideias expostos ao aprendiz sejam relacionados por este de forma não literal, ou seja, não ao pé da letra e não de forma arbitrária. Isso pode ser observado nas respostas destes 15 alunos, que demonstraram a capacidade de explicar à sua maneira, de acordo com sua compreensão e com suas próprias palavras tanto as características destes seres quanto suas relações com a saúde humana.

Ainda nesse sentido, Pelizzari et al. (2002) [10], apontam que: "sugere-se que os alunos 'realizem aprendizagens significativas por si próprios', o que é o mesmo que aprender a aprender. Assim garante-se a compreensão e a facilitação de novas aprendizagens ao ter-se um suporte básico na estrutura cognitiva prévia construída pelo sujeito".

Categoria 2: Capacidade de aplicar o conhecimento - foi possível verificar a ocorrência desta categoria em apenas seis alunos $(15,7 \%)$, em cujas respostas o conhecimento foi utilizado em uma outra perspectiva.

Como já explicitado por Moreira (2011a) [13], os processos avaliativos de ocorrência de aprendizagem significativa devem estar voltados para a compreensão, captação de significados e principalmete a capacidade de transferencia do conhecimento para situações não conhecidas, não rotineiras. Isso caracteriza substancialmente a categoria supra citada, pois para evidênciar que ocorreu a aprendizagem significativa, uma das formas é identificar essa capacidade de aplicar o conhecimento em outras situações, principalmente em seu cotidiano, como nos exemplos descritos pelos alunos 27 e 37 :

A27: "Eles são muito presentes em nosso cotidiano e às vezes passavam despercebidos, vou usar as informações que eu adiquirir para me previnir de várias doenças.”.

A37: "Se eu fosse um vírus eu iria entrar em uma célula, depois reproduzir e transmitir diversas doenças nas pessoas."

Essa descrição da relação com outro organismo como algo danoso, principalmente ao se definir como um vírus que "se instalaria em um hospedeiro e transmitiria doenças" é uma forma básica de aplicação, pois os mesmos não disseram que poderiam utilizar os organismos para produzir coisas novas, mas apenas se colocaram no lugar dos micro-organismos ou disseram que usariam os novos conhecimentos para se proteger deles. Mas já é um começo.

Diante disso é importante considerar que "a estrutura cognitiva é um complexo organizado de todo o conhecimento que temos, no entanto a estrutura cognitiva não é estática, é dinâmica, vai mudando á medida que aprendemos significativamente" [12].

Categoria 3: Captação de significados - foi evidenciada uma grande quantidade de alunos $(78,9 \%)$, que conseguiu atribuir um sentido ao conteúdo discutido em sala de aula.

Esta captação de significados é enfatizada por Mansini e Moreira quando descrevem que "quando a aprendizagem de novos conhecimentos é significativa, captamos os significados, entendemos, somos capazes de aplicá-los no domínio de situações, inclusive novas" [12]. 
Desta forma os principais significados captados pelos alunos estiveram relacionados aos cuidados com as doenças transmitidas por micro-organismos, principalmente os vírus e também a distinção entre micro-organismos que podem causar doenças e aqueles que podem ser importantes para a natureza, por exemplo, na decomposição, e ainda aqueles que entenderam os microorganismos como sendo importantes na indústria alimentícia e fabricação de vacinas. Como demonstram os exemplos das seguintes respostas:

A7: "Os fungos são usados para produção de alguns alimentos como o queijo, outros são comestiveis, como o exemplo do cogumelo.".

A23: "Embora alguns causem doenças, há alguns que são importantes, como ,por exemplo, aqueles que atuam na decomposição, na indústria ou os que são usados pra fazer vacinas contra algumas doenças.".

Categoria 4: Diferenciação progressiva - ocorre quando o aluno demonstra que a organização do conhecimento em sua estrutura cognitiva se faz de forma hierárquica, partindo do mais geral para o mais específico. Sendo está diferenciação progressiva um dos princípios mais importantes da teoria da aprendizagem significativa, tanto no sentido de estruturação dos conteúdos a serem abordados em sala de aula, quanto na forma de organização e estruturação deste conhecimento na estrutura cognitiva do aluno.

Nesta categoria, as respostas de apenas oito (21\%) alunos foram reconhecidas. Esta categoria possuiu relação com a primeira, onde o aluno deve ter a capacidade de explicar, mas acrescenta-se que essa explicação deve fazer sentido e possuir uma organização hieráquica. Sendo assim, se um aluno conseguiu organizar seus conhecimentos e estruturou-os para dar uma explicação, pode-se considerar que está desenvolvendo uma Aprendizagem Significativa e consequentemente a diferenciação progressiva.

Os alunos não foram muito prolixos em suas respostas, mas ao observarmos a quantidade de categorias de AS que cada aluno foi capaz de alcançar, notamos que o assunto envolveu a maior parte dos alunos. Houve seis alunos $(15,7 \%)$ que não responderam as questões não sendo possível concluir acerca de sua aprendizagem. Foi possível identificar que 42,1\% dos alunos conseguiram alcançar uma categoria de AS, sendo que a principal foi a captação de significados. Outro grupo de alunos, $21 \%$, conseguiu aprender o conteúdo de forma significativa em duas categorias, "explicar" e "captar significados".

Essa diversidade na quantidade de categorias observadas no discurso escrito dos alunos pode estar relacionada a diversas variáveis, relacionadas a cada aluno, desde a vontade ou predisposição para aprender até uma maior habilidade no estudo do conteúdo proposto. Os alunos cujas respostas estão presentes em três $(13,1 \%)$ ou quatro $(7,9 \%)$ categorias, ao serem analisados durante as observações in loco, ou nas gravações das aulas, são aqueles que apresentavam maior predisposição para aprender, interagiam mais entre si e com o professor, questionavam mais (mesmo que de forma mais tímida), buscavam um maior entendimento e demonstravam comportamentos em todas as aulas que evidenciavam a ocorrência da AS.

Os alunos que apresentaram, no discurso escrito, uma ou duas categorias de AS, não demosnstraram uma efetiva interação em todos os encontros. $\mathrm{O}$ caso dos alunos que não tiveram em suas respostas o reconhecimento de nenhuma das categorias de AS, foram aqueles que, por algum motivo, não demonstraram predisposição a aprender e isso, infelizmente, foi algo que o professor/pesquisador não conseguiu modificar, uma vez que mesmo com as tentativas de mobilização da turma, em alguns momentos, determinados alunos não foram afetados por essa mobilização, e deve-se considerar também o componente individual de interesse do aluno pela disciplina.

Neste sentido Ausubel, citado por Cavalcanti (2016) [21], fala sobre o "estilo cognitivo", explicando que o mesmo está relacionado a formas individuais de organizar cognitivamente os conhecimentos, o que pode estar relacionada à forma da personalidade ou a genética; o autor ainda traz aspectos relacionados à motivação, emoção e cognição, como fatores relacionados a este estilo.

É importante destacar que, de maneira geral, mesmo com alguns alunos interagindo, a turma, como um todo, mantinha um comportamento mais passivo. Acredita-se que isso se deve a forma como são ministradas as aulas na instituição. Neste sentido Moreira e Masini (2001) [11] argumentam que: 
O ensino requer reciprocidade de responsabilidade, porém aprender significativamente é uma responsabilidade do aluno que não pode ser compartilhada pelo professor. Para aprender significativamente, o aluno tem que manisfestar uma disposição de relacionar de maneira não arbitrária, a sua estrutura cognitiva os significados que capta dos materiais educativos, potencialmente significativos [...].

Quando se fala em predisposição para aprender, assim como coloca Moreira (2011b) [14], é necessário esclarecer que essa predisposição não significa necessariamente uma motivação, ou o fato de o aluno apreciar alguma disciplina, vai além e, por algum motivo, o aprendiz se predispõe em relacionar sempre diferenciando e integrando, de forma interativa, os conhecimentos em sua estrutura cognitiva.

Os resultados obtidos foram bastante satisfatórios uma vez que conseguimos evidenciar na maioria os alunos a ocorrência de AS onde esses expressaram em suas respostas o que de primordial é necessário para ocorrência desta aprendizagem, que são os conhecimentos descritos de forma não literal nem arbitrária. Acreditamos que, se estes mesmos alunos permanecessem tendo aulas com abordagens baseadas em instrumentos como as UEPS, o percentual de evidências aumentaria consideravelemente, pois a turma demonstrou ter grande potencial, precisando de "mobilização metodológica".

Considerando o cotidiano das escolas, em especial na instituição campo desta pesquisa, no período de desenvolvimento das aulas tivemos que lidar com imprevistos e modificação no planejamento, algo considerado "normal" nos contextos escolares. A dinâmica da sala de aula nem sempre possibilita que o professor tenha controle de todas as variáveis. Além disso, o conteúdo a ser explorado, por vezes exige a inclusão e discussão de elementos que dificultam a execução do conteúdo previsto em termos de proposta didática [21].

Desta forma, é determinante a construção de métodos e instrumentos de ensino que permitam esta flexibilização para serem utilizados nas aulas. Também são necessárias adaptações pertinentes para cada contexto, seja de conteúdos ou do ambiente onde a escola está inserida.

Nesse sentido, após as adequações implementadas no instrumento de ensino utilizado, como a distribuição do conteúdo de forma mais adequada ao tempo de aula disponível, foi identificado que durante o desenvolvimento da UEPS, nem todos os alunos conseguiram aprender o que de fato foi proposto. De acordo com as observações feitas e anotadas no diário de campo e gravações das aulas, observamos algumas dificuldades, durante a aplicação da UEPS. No quadro 2 são sintetizadas as dificuldades apresentadas pelos alunos no desenvolvimento da UEPS, as quais designo como variáveis internas.

Quadro 2 - Dificuldades observadas nos alunos que podem ter interferido no desenvolvimento da AS.

\begin{tabular}{cl}
\hline DIFICULDADE DOS ALUNOS & \multicolumn{1}{c}{ DETALHAMENTO } \\
\hline Ausência de conhecimento prévio & $\begin{array}{l}\text { Quando o aluno não demonstra possuir } \\
\text { conhecimentos prévios, ou conceitos sobre o } \\
\text { conteúdo a ser estudado. }\end{array}$ \\
\hline Obstáculo Epistemológico & $\begin{array}{l}\text { Quando a ideia ou conceito existente na estrutura } \\
\text { cognitiva do aluno, atua bloqueando um novo } \\
\text { conhecimento científico. }\end{array}$ \\
\hline Termos complexos da Disciplina & $\begin{array}{l}\text { Muitos termos, nomes científicos, terminologias } \\
\text { difíceis de entender, de pronunciar e, muitas vezes, } \\
\text { fora do contexto do aluno. }\end{array}$ \\
\hline Sobrecarga dos componentes curriculares & $\begin{array}{l}\text { Muitas disciplinas e exigências de atividades, } \\
\text { trabalhos e exames no período letivo. }\end{array}$ \\
\hline Falta de predisposição do aluno em aprender & $\begin{array}{l}\text { Falta de vontade demonstrada pelo aluno para } \\
\text { adquirir um novo conhecimento, dar significado e } \\
\text { compreendê-lo. Pode estar relacionado a outros } \\
\text { problemas particulares do aluno não detectados } \\
\text { pela pesquisa. }\end{array}$ \\
\hline
\end{tabular}


É certo que ao desenvolver uma aula, o objetivo do professor é que o aluno consiga aprender, aprender de forma significativa, para que possa por meio desse conhecimento, resolver questões dentro e fora da escola, no entanto é certo também que nem sempre todos os alunos conseguirão se apropriar deste conhecimento. Uma das primeiras dificuldades evidenciadas está relacionada aos conhecimentos subsunçores, que são fatores primordiais para o desenvolvimento de uma aprendizagem significativa, e não foram identificados nos diálogos iniciais das primeiras atividades desenvolvidas na UEPS. A inexistência dos mesmos ocasionou, consequentemente, dificuldades para a aprendizagem.

Segundo Moreira (2011b) [14] "Ausubel chama de subsunçores os conhecimentos prévios que em um processo interativo servem como ancoradouro ou ideias âncora para dar sigificado ao novo conhecimento.". Os subsunçores são os responsáveis por parte da AS que se desenvolve no aprendiz, representa o fator mais importante para o desenvolvimento da aprendizagem, aquilo que o aluno já sabe e cabe ao professor descobrir para ensinar de acordo com as necessidades identificadas.

Outra dificuldade percebida foi a existência de obstáculos epistemológicos, o que pode ser exemplificado pelo fato da maioria dos alunos que se manifestou nas aulas ter a ideia prévia de que os micro-organismos só possuem papel danoso, de causadores de doenças. Foi identificado no discurso dos alunos, registrado em diário de campo, o quanto que as palavras, os termos relacionados ao tema estudado eram difíceis para eles, dificultando o entendimento do que estava sendo abordando. Essa situação que muitas vezes é percebida também em outras disciplinas, como as de cálculo, por exemplo, acaba sendo uma realidade. Muito dessa percepção sobre a disciplina ser complexa ou difícil, pode ter origem na forma como a mesma é trabalhada em sala de aula e não necessariamente na complexidade dos conteúdos.

Outra dificuldade também mencionada pelos alunos, em relação à aquisição de conhecimentos, foi relacionada à sobrecarga dos componentes curriculares, ou seja, são muitas disciplinas para estudar e, ao mesmo tempo, ter um bom desempenho. Considero como um dos fatores imprescíndíveis para a ocorrência da AS, a última dificuldade observada, que é a predisposição do aluno para aprender. Sem essa vontade, sem essa mobilização pessoal, existirá concretamente a dificuldade e a impossibilidade de se proporcionar a AS.

Essa falta de predisposição para aprender foi percebida por meio do comportamento de alguns alunos durante as aulas. Isso pode ser exemplificado pela falta de atenção durante as aulas, por diversos motivos, mas também pelo uso de aparelho celular durante a aula, ainda que seja proibido pela escola, resultando em alunos que ficam mais afastados, "no fundo da sala", não demonstrando interesse em participar das discussões, não entregando trabalhos ou atividades no período de desenvolvimento da UEPS.

Sendo essas dificuldades, consideradas recorrentes no cotidiano escolar, encontrar formas de articular as aulas, para minimizá-las, é tarefa contínua do professor que se vê imerso a tantas adversidades para alcançar seus objetivos. No caso dessa última dificuldade mencionada, Masini e Moreira (2017) [12], comentam que "a predisposição para aprender, o querer aprender, a intencionalidade do aprendiz, é outro fator fundamental; o ser humano poderá aprender de forma significativa se quiser aprender; por alguma razão deve ter a intenção de aprender."

Além disso, Nuncio (2016) [22] comenta que para o desenvolvimento de uma AS mais crítica é necessário que o aprendiz seja um questionador, que passe a problematizar os conteúdos estudados e esteja disposto a aprender.

Neste sentido Pozo (2002) [23] descreve que, o aluno precisa desenvolver certo esforço para aprender e que muito do que se fala sobre a falta dessa predisposição para aprender pode estar relacionado ao fato do aluno não conseguir relacionar de forma significativa o que estuda com as suas vivências. Desta forma o aluno não encontra sentido para aprender.

Em vista disso, voltamos a citar a importãncia de conhecer os subsunçores presentes na cognição do aluno. Lemos (2011) [19] explica que, "[...] quando a estrutura cognitiva do indivíduo não possui subsunçores diferenciáveis e estáveis para ancorar (subsumir) a nova informação, o indivíduo a armazenará de forma literal e não substantiva."

Cavalcanti (2016) [21] aponta que, quando se considera o contexto educacional, é imprescindível a busca e reconhecimento do que os estudantes já sabem, e que isso deve ser feito antes da apresentação dos novos conhecimentos. Então, se este conhecimento prévio, esses 
subsunçores, não existe, consequentemente há dificuldade para a ocorrência de AS, o que aconteceu com alguns alunos da turma em questão.

Considerando a citação de Moreira e Masini (2001) [11], percebe-se a importância dos subsunçores e, que estes podem não existir ou se existirem, podem atuar de forma contrária, inibindo ou limitando o desenvolvimento de determindo conhecimento, como observado no estudo. [...] a casos em que o conhecimento prévio pode ser bloqueador, funcionar como o que Gaston Bachelard chamou de obstáculo Epistemológico. Por exemplo, a ideia de corpúsculo como uma "bolinha" invisível, com uma massa muito pequena, ocupando um espaço muito pequeno, dificulta enormemente a aprendizagem significativa do que seja uma partícula elementar [11].

$\mathrm{Na}$ escola é muito frequente o desenvolvimento de atitudes negativas acerca de algumas matérias de ensino, nas quais a aprendizagem é normalmente mecânica. É comum os alunos dizerem que "odeiam" as disciplinas, que só querem passar de ano por não aguentarem a memorização de definições e fórmulas que deverão ser repetidos nas provas [12].

Diante das considerações tecidas, fica clara a importância de considerar as particularidades vivenciadas em sala de aula. O professor além de se preocupar com estrátégias, instrumentos de ensino e objetivos de aprendizagem, deve também compreender em qual contexto a escola e os alunos estarão inseridos para, uma vez conhecendo as variáveis e dificuldades cotidianas da aprendizagem de seus alunos, atuarem no intuito de minimizá-las e extingui-lás.

Além destes fatores citados até agora como variáveis internas, temos também as variáveis externas que, de alguma forma, podem ter interferido no desenvolvimento da UEPS e consequentemente no desenvolvimento de uma aprendizagem mais significativa.

A principal variável externa foi o "tempo de aula". A diminuição do tempo das aulas foi decorrente de ser o horário inicial de funcionamento da escola e, por isso, esteve associado aos atrasos decorrentes do uso de transporte escolar. Nesse horário, também ocorria a apresentação de avisos e recados escolares.

Esta variável é, em todas as disciplinas, o fator que determina o rítmo das aulas, uma vez que os professores precisam "vencer" o conteúdo em aulas de $50 \mathrm{~min}$. Quando ocorrem interferências neste "tempo", o professor precisa improvisar e muitas vezes não consegue expor e discutir o conteúdo de forma adequada, o que implica em menos possibilidades de aprendizagem por parte dos alunos.

Neste sentido, as atividades propostas na UEPS foram planejadas para aulas de 50 minutos, que foi o tempo disponibilizado pela escola, entretanto as inúmeras intercorrencias relacionadas ao tempo, levaram, em média, a uma perda de aproximadamente $10 \%$ do horário de cada aula.

Nuncio (2016) [22], em seu trabalho sobre UEPS no contexto do ensino de ciências destacou, também, o fator tempo como um problema em suas aulas. Em virtude do tempo, nem todas as etapas puderam ser rigorosamente desenvolvidas com os participantes, mas todos os passos foram apresentados e brevemente discutidos.

A variável tempo também está relacionada ao horário da disciplina, que ocorria no primeiro horário do turno da manhã. A primeira aula sempre acabava ficando mais curta que as demais. Este fato é importante na discussão do cotidiando escolar, pois o professor não pode se recusar a ter suas aulas nos primeiros horários da escola. Na escola em questão, por se tratar de uma escola de campo, que tem a maior parte de seu público oriunda das zonas rurais, os alunos, em sua maioria, dependiam de transporte escolar para chegar à escola. O horário de transporte não é uma prerrogativa do aluno, mas uma consequencia de sua situação sócio-econômica.

Outro fator relacionado ao tempo foram as atividades burocráticas da escola, decorrentes do início do período letivo. A direção/coordenação utilizava os primeiros horários para dar avisos nas turmas, esclarecimentos, contribuindo para a diminuição do tempo previsto para as aulas.

Tanto variáveis internas como externas dificultam o processo de aprendizagem significativa e, por isso, devem ser discutidas durante o período de planejamento escolar de cada ano letivo, baseadas no que ocorreu no ano anterior, para tentar minimizá-las. 


\section{CONCLUSÃO}

Visto as dificuldades para se desenvolver os conteúdos de Biologia de forma mais significativa para os alunos do ensino médio, o professor vive uma constante busca de formas para melhorar seu ensino e proporcionar essa aprendizagem. No presente trabalho, foi possível reconhecer a importância de atuar a partir do embasamento de uma teoria da aprendizagem, que dá suporte a prática docente, ajudando o professor a definir seus objetivos de ensino e a utilizar métodos e instrumentos que viabilizem uma melhor aprendizagem.

Neste trabalho, foi evidente que as Unidades de Ensino Potencialmente Significativas podem contribuir para o desenvolvimento da AS, e esta é uma abordagem capaz de contribuir com uma diversidade de métodos, instrumentos e pela sua dinâmica de funcionamento também como motivadora para a aprendizagem dos alunos.

A UEPS proposta aqui, apresentou além das características mencionadas acima, o fato de poder estruturar os conteúdos de ensino de forma mais organizada e coerente, assim como dinamizá-lo, uma vez que era um conteúdo, presente no cotidiano dos alunos, porém não visível aos olhos e que pode ser apresentado sem precisar de materiais sofisticados, ou componentes de laboratórios, por exemplo, e isso sem dúvida é um grande benefício para o professor de escolas públicas que vivenciam a falta deste tipo de recurso.

De acordo com o que foi analisado, foram obtidas algumas respostas aos questionamentos feitos a priori. A AS é desenvolvida de forma gradativa, no dia a dia, por meio de tarefas que estimulam a participação dos alunos, mas também é necessário que estes troquem entre si os significados e tenham a predisposição de aprender.

No que se refere às variáveis, tanto internas quanto externas, presentes no período do estudo (pouco tempo para as aulas, a falta de conhecimentos prévios, a falta de predisposição para aprender, entre outros), conclui-se que, mesmo com a ocorrência e identificação das mesmas, a UEPS foi eficaz, uma vez que por meio dela alguns alunos conseguiram desenvolver a AS.

Além dessas variáveis é importante considerar, as dificuldades individuais dos alunos, aquilo que impediu o desenvolvimento da AS. Os resultados do estudo evidenciaram, assim como a própria teoria destaca, que os conhecimentos prévios dos alunos são de suma importância para a AS. Aqueles alunos que não os possuíam ou que tiveram dificuldade para verbalizá-los, tiveram maiores dificuldades em aprender, mesmo tendo sido utilizado um organizador prévio.

No entanto, o que chamou bastante a atenção é que o aluno aprenderá de forma significativa se assim quiser (claro que, desde que as condições mínimas sejam fornecidas) o que corrobora com os dizeres da TAS. Foi percebido, que alguns participantes, não tinham essa predisposição, fato percebido tanto nas observações in loco, quanto nas respostas ao questionário e atividades propostas no período do estudo.

Acreditamos, pois, que este estudo contribui para entendermos como se processa a AS em uma escola real, com métodos possíveis de serem utilizados na aprendizagem dos alunos, tanto da turma estudada quanto de qualquer outra turma, pois, pela metodologia utilizada, verificamos que alguns alunos conseguiram relacionar os conhecimentos científicos adquiridos na escola com as situações cotidianas que vivenciam. Resta agora tentar implementar formas de envolver mais alunos neste processo. Mas esta será uma nova etapa.

\section{AGRADECIMENTOS}

As autoras expressam seus agradecimentos a CAPES pela concessão da bolsa à primeira autora para a realização do Curso de Pós-Graduação em Ensino de Ciências e Matemática (Mestrado) da UFS (Processo \# 88882.459865/2019-01). Agradecemos também aos funcionários da escola onde foi realizada a pesquisa pela solicitude e acolhimento.

\section{REFERÊNCIAS BIBLIOGRÁFICAS}

1. Motokane MT. Sequências didáticas investigativas e argumentação no ensino da ecologia. Rev Ensaio. 2015;17:115-137, doi: 10.1590/1983-2117201517s07

2. Krasilchik M. Prática de ensino de biologia. 4ed. São Paulo: Edusp; 2011. 
3. Cabelleira PA. Dispositivos complexos de aprendizagem no ensino de ciências: o imaginário mundo da microbiologia. [Dissertação]. Caçapava do Sul (RS): Programa de Pós-Graduação em Ensino de Ciências. Universidade Federal do Pampa; 2018.

4. BRASIL. Ministério da Educação - MEC, Secretaria de Educação Média e Tecnológica - Semtec. PCN + Ensino Médio: orientações educacionais complementares aos Parâmetros Curriculares Nacionais Ciências da Natureza, Matemática e suas Tecnologias. Brasília: MEC/Semtec, 2002.

5. Bezerra HPS. A Contextualização de conhecimentos no ensino de microbiologia com base na teoria da aprendizagem significativa. [Dissertação]. Seropédica (RJ): Programa de Pós-Graduação em Educação Agrícola. Universidade Federal Rural do Rio de Janeiro; 2016.

6. Antunes $\mathrm{CH}$, Pillegi M, Pazda AK. Por que a visão científica da microbiologia não tem o mesmo foco na percepção da microbiologia no ensino médio? Anais do III Simpósio Nacional de Ensino de Ciências e Tecnologia. Área de Ensino de Biologia; 26-28 de setembro de 2012; Ponta Grossa, PR. ISSN: 21786135.

7. Lima JMM, Ayub CSLC, Morales AG, Júnior AL. Aproximação entre a teoria histórico-crítica e a aprendizagem significativa: uma prática pedagógica para o ensino de Biologia. Aprendizagem Significativa em Revista. 2012;2(2):54-64.

8. Moreira MA. Teorias da Aprendizagem. 2ed. ampliada. São Paulo: E.P.U.; 2015.

9. Portilho E. Como se aprende? Estratégias, estilos e metacognição. 2ed. Rio de Janeiro: EDITORA; 2011.

10. Pelizzari A, Kriegl ML, Baron MP, Finck NTL, Dorocinski SI. Teoria da aprendizagem significativa segundo Ausubel. Rev PEC. 2002;2(1):37-42.

11. Moreira MA, Masini EFS. Aprendizagem Significativa: a teoria de David Ausubel. 2ed. São Paulo: Centauro; 2001.

12. Masini EFS, Moreira MA. Aprendizagem significativa na escola. Curitiba (PR): CRV; 2017.

13.Moreira AM. Aprendizagem significativa: a teoria e textos complementares. São Paulo: Editora Livraria da Física; 2011(a).

14.Moreira AM. Unidades de ensino potencialmente significativa- UEPS. Aprendizagem Significativa em Revista. 2011(b);1(2):23-63.

15.Ribeiro TN. O ensino de razões trigonométricas nos triângulos retângulos a partir de situações aplicadas à Física: Um estudo baseado nas unidades de ensino potencialmente significativas (UEPS). [Tese]. São Paulo (SP): Programa de Pós-Graduação em Educação Matemática. Universidade Anhanguera de São Paulo; 2015.

16.Flick U. Desenho da pesquisa qualitativa. Porto Alegre: Artmed; 2009.

17.Ludke M, Andre MEDA. Pesquisa em Ação: abordagens qualitativas. 2ed. Rio de Janeiro: E.P.U.; 2015.

18.Moraes R, Galiazzi C. Análise textual discursiva. 2 ed., Ijuí (RS): Ed. Unijuí; 2011.

19.Lemos ES. A Teoria da aprendizagem significativa e sua relação com o ensino e com a pesquisa sobre o ensino. Aprendizagem Significativa em Revista. 2011;1(3):47-52.

20. Ausubel DP. Aquisição e Retenção de conhecimento: Uma perspectiva cognitiva. Lisboa: Plátano; 2003.

21.Cavalcanti J. Unidade de ensino potencialmente significativa para estudo do sistema respiratório humano no ensino fundamental II. [Dissertação]. Passo Fundo (RS): Programa de Pós-Graduação em Ensino de Ciências e Matemática do Instituto de Ciências Exatas e Geociências. Universidade de Passo Fundo; 2016.

22.Nuncio AP. Contribuições de unidades de ensino potencialmente significativa (UEPS) para a disciplina de ciências do ensino fundamental. [Dissertação]. Caxias do Sul (RS): Programa de Pós-Graduação em Ensino de Ciências e Matemática. Universidade de Caxias do Sul; 2016.

23.Pozo JL. Teorias Cognitivas da Aprendizagem. Porto Alegre: Artmed; 2002.

24. Ausubel, DP. The Psychology of meaningful verbal learning. New York: Grune and Stratton, 1963. 